\title{
INTERACTIVE SPACES \\ TOWARDS COLLABORATIVE STRUCTURING AND UBIQUITOUS PRESENTATION IN DOMESTIC ENVIRONMENTS
}

\author{
Kaj Grønbæk and Marianne Graves Petersen \\ Center for Interactive Spaces \\ Department of Computer Science \\ Åbogade 34, DK-8200 Århus N \\ kgronbak, mgraves@interactivespaces.net
}

\begin{abstract}
This paper analyses the use of media and material in private homes based on empirical studies in a project on designing interactive domestic environments. Based on the analyses we propose a Domestic Hypermedia infrastructure (DoHM) combining spatial, context-aware and physical hypermedia to support collaborative structuring and ubiquitous presentation of materials in private homes. With DoHM we propose establishing new relationship between digital and physical hyperspaces, folding hyperspaces into the physical space of the household. Thus we strive to combine the qualities of physical domestic materials and spaces with the flexibility and dynamics of digital hyperspaces. We propose a variety of new ubiquitous home appliances called MediaWall, MediaTable, MediaTray and MediaPort, which address these issues.
\end{abstract}

Keywords

Interactive spaces, augmented reality, context awareness, ubiquitous hypermedia, domestic technology, multimedia, physical hypermedia,

\section{INTERACTIVE SPACES}

Designing interactive spaces is an effort which combines the competencies of architects and computer scientists. In Center for Interactive Spaces, we take activities as the common starting point when we co-design space and technology in an iterative design process, where neither defines the other nor is taken for granted but both dimensions are manipulated and synthesized into innovative design concepts. Designing interactive technology in this perspective has a number of implications. First, where much focus in the field of domestic technologies has been on exploiting technological possibilities to support awareness and communication amongst people who are not co-located (Hutchinson et al. 2003, Mynat et al. 2003), a focus on interactivespaces as described above implies support for interaction amongst people, who are co-located. In a domestic context, this aspect becomes crucial, as we currently see an increased digitization of domestic material, e.g. photos, movies, calendars, recipes, notes, banking, messages from school etc. increasingly become digitized and thus no longer have an inherent physical form. Digital materials often reside on a personal computer, which provides single user access to materials rather than engaging multiuser experiences which are highlighted in an interactivespaces perspective. Moreover, when studying how physical domestic materials are organised in homes, the actual physical layout of the home provides an implicit structuring mechanism for these materials. Thus, a perspective of interactivespaces implies carefully considering the relationship between digital and physical spaces. In this work, we adopt a folding strategy where the digital spaces is folded into the physical space seeking to maintain the qualities of both types of spaces Addressing a domestic space moreover has a number of consequences. Historically, the workplace has undergone a similar transition of digitization as we currently witness in homes. However, the home is quite different from the workplace in many respects. Activities in the home are less task-oriented (Monk 2000); the rationalities of work in terms of production, efficiency and organization of labour do not necessarily transfer to the home (Crabtree et al. 2002). Moreover inhabitants continuously re-configure and appropriate their homes both to 
express their identity to the outside world (Palasmaa 1994), but equally to capture their own history and biography (Silverstone et al. 1992). Thus homes have their own aesthetics where the visible, physical "information material" often play a role in expressing identity e.g. in terms of the books being read or the music listened to by the inhabitants. These qualities of the domestic environment are important to understand when designing domestic interactive spaces. Thus in order to design future domestic interactive environments, we argue that it is necessary to study the characteristics of the existing use of both physical and digital materials in homes today. While we are not the only one to take this point of stance, our focus is different from other studies. E.g. some groups have focused on understanding patterns of domestic routines (Crabtree et al 2002a, 2002b, Tolmie et al. 2002) where we have focused more broadly on eliciting the different roles domestic information materials may have, not restricted to patterns of routine. Others have investigated what constitutes the home experience (Eggen et al. 2003) more generally, but this study did not reveal how specific materials formed part of constituting the home experience. Our studies are inspired by the studies by (Crabtree et al. 2002a,2002b), who investigate how the physical space of the home is used to coordinate the handling of paper mail, but our focus is on materials more broadly than paper mail. Compared to the Jigsaw domestic component system proposed by Humble et al (2003), we take a material centered approach. We have focused on the organization of domestic material and on how we can provide a seamless folding between the physical and digital material spaces. Where Humble et al.(ibid) focus on supporting transformations between digital and physical material, we focus on linking and integrating the physical and the digital.

The paper is structured as follows: Section 2 describes a qualitative approach to the study of 6 different types of households and section 3 outlines the challenges identified in this study for the design of domestic interactive spaces. Section 4 introduces a domestic hypermedia infrastructure (DoHM) which seeks to meet the challenges identified in section 3. Section 5 gives examples of appliances, which fold hyperspace into the physical home environment. Section 6 discusses related work. Section 7 concludes the paper.

\section{EMPIRICAL STUDIES}

We have undertaken qualitative empirical studies in six private homes inhabited by different types of families, ranging from singles, over families with children living at home, to communes. We visited each household once and stayed for approximately one and a half to two hours each place. In each home, we asked the inhabitants to take us on tours around the house (Petersen and Baillie 2001). We focused on how people organize domestic information materials in general, i.e. media, letters, memo lists, newspapers etc., and we interviewed people about the rationale, and history of the physical placements of both physical and digital materials. We asked about ownership and possible conflicts around placement of materials (Mynatt et al. 2003). We captured data from the homes through video recordings, and pictures. The six visits form part of a continued investigation into domestic technology use of our own (Petersen et al. 2002, Kjær et al. 2000) as well as others (Crabtree et al. 2002b, Mynatt et al. 2003).

\section{Information material in homes}

Taking tours in private homes reveals a wealth of information materials with hypermedia qualities, which are literally distributed all over the house. Table 1 holds a non exhaustive list of domestic materials, which are grouped into categories with different characteristics. The purpose of this list is to illustrate the richness and heterogeneity of domestic materials, rather than providing an exhaustive and complete list. 


\begin{tabular}{|l|l|l|}
\hline Types of material & Example material & Characteristics \\
\hline Media & $\begin{array}{l}\text { Movies, music, pictures, books, news, } \\
\text { magazines, games, news, computer } \\
\text { applications }\end{array}$ & $\begin{array}{l}\text { Carefully chosen, bought and stored } \\
\text { Used for leisure purposes }\end{array}$ \\
\hline $\begin{array}{l}\text { Home } \\
\text { administration } \\
\text { tools }\end{array}$ & $\begin{array}{l}\text { Calendars, memo lists, tickets, contact } \\
\text { information, notes for other family } \\
\text { members, letters from school, } \\
\text { kindergarten etc }\end{array}$ & $\begin{array}{l}\text { Ongoing administration } \\
\text { Used as tools for coordination }\end{array}$ \\
\hline Domestic task & Recipes, manuals, handbooks & Support domestic tasks \\
\hline $\begin{array}{l}\text { Manifestations of } \\
\text { social life }\end{array}$ & $\begin{array}{l}\text { Invitations, greetings, personal letters, } \\
\text { jokes }\end{array}$ & $\begin{array}{l}\text { Maintaining social relations } \\
\text { Capturing history } \\
\text { Used as decoration }\end{array}$ \\
\hline $\begin{array}{l}\text { Communication } \\
\text { with official } \\
\text { authorities }\end{array}$ & Letters from bank, bills, & $\begin{array}{l}\text { Information push } \\
\text { Often little affection towards } \\
\text { material }\end{array}$ \\
\hline $\begin{array}{l}\text { Decoration } \\
\text { materials }\end{array}$ & Pictures, souvenirs, seasonal objects & $\begin{array}{l}\text { Capturing history } \\
\text { Expressing identity }\end{array}$ \\
\hline Work materials & Electronic mail, word documents etc. & Support work tasks \\
\hline
\end{tabular}

Table 1: The heterogeneity of domestic materials and their use

We do not wish to claim that the categories below are rigid and disjunctive, e.g. a calendar is also a manifestation of social life. The purpose is rather to illustrate that home contain a complex collection of various heterogeneous materials of very different nature. Materials which are kept for different purposes, e.g. calendars, messages from school, shopping lists support the practical coordination of home life whereas various media are consumed and used for leisure purposes. Media are also most often actively selected, bought and carefully stored, whereas letters of communication with official authorities are pushed regularly upon the household members. As suggested in the following, these different forms of information materials are also often treated quite differently. One tendency, which we do observe across the different types of materials, however, is an increased digitization of domestic materials. This happens with e.g. music (Premkumar 2003), photos, and letters from bank. This has both negative as well as positive side-effects. The mission of this paper is to learn how to take the best from both sides and combine into visions on concepts for future domestic hypermedia systems.

\section{CHALLENGES TO DOMESTIC HYPERMEDIA INTERFACES}

In the following, we illustrate how the context of the home provides new challenges to hypermedia structuring mechanism. While these challenges are specific to the domestic sphere, we suggest that they are fruitful provocations for new conceptions of hypermedia more generally, and thus are also worth investigating in other contexts.

\section{Linking digital and physical material}

The homes contain a number of implicit links between digital and physical material that are currently not well supported. Taking the case of digital photos we saw an instance where digital photos from a wedding had been developed onto paper in order to distribute them to others, and to make a physical collection of the pictures. In this case, the co-existence of the digital and physical form is important, however, there is no direct link between the physical and digital versions of the picture. E.g. there is AJIS Special Issue 
no easy way of tracing the digital version of a physical photo. The only means of creating a link is through annotating the physical and digital versions by hand. We saw no instances where this had happened in the homes we visited. We saw an example of this, however, with photos developed from negatives. As can be seen in

Figure 2, time-stamps on post-its with regular intervals in both collections provided means for linking the composites together. Thus our studies suggest a need for linking support between digital and physical material, allowing for the co-existing of forms, rather than supporting transformation between forms as suggested by e.g. Humble et al. (2003)..

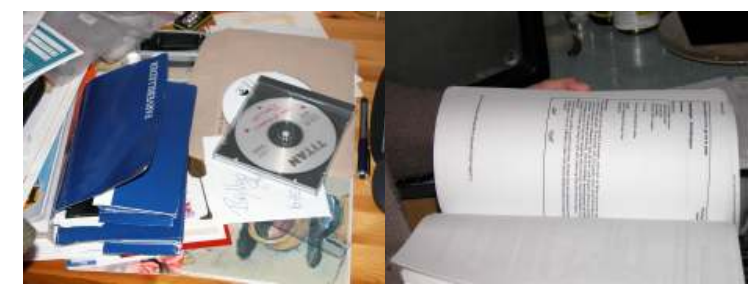

Figure 1: Left: unlinked digital photos and printed versions. Right: recipe printed from the web with printed URL

An additional example is the case of recipes printed from the web, right picture in

Figure 1. Here we find a one-directional link from the printed version to the digital material. Again we see how the digital and physical versions co-exist in homes as the physical version is more robust in the context of the kitchen, than the mobile computer of the household. However, both when it comes to physical pictures and physical recipes there are problems with searching through the material for specific contents as this relies on the inhabitant to produce metadata or in other ways impose structure on the physical material. One of the people we visited explained that it was much easier to re-print the recipe from the web rather than trying to find the printed version in the unstructured collection of recipes. Further, there are a lot of implicit links between physical materials in the home.

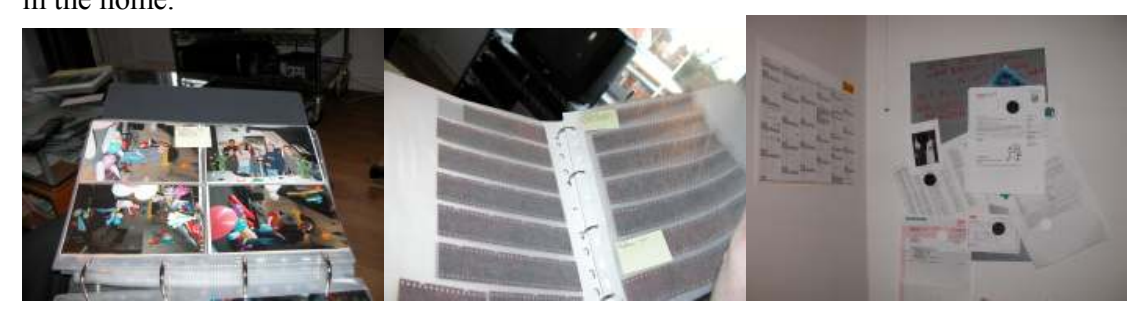

Figure 2: Left and middle: PostIts with dates provides link between composites of physical photos and corresponding negatives Right: Calendar and notice board in kitchen

E.g. Figure 2, right shows an example where the picture on the notice board of the wedded couple is implicitly linked to a date on the nearby calendar. The same holds true for the football match schedule on the notice board. While both calendar and football schedule may well be digitized and linked together in terms of dates, this would miss the important quality of notification through the persistent visibility, which characterizes physical papers on a notice board in a busy place of the 
home. Thus as discussed in the following, key to designing successful hypermedia support is to understanding the roles of different domestic surfaces.

\section{Understanding domestic surfaces}

Crabtree et al.(2002a) were among the first to spell out in details how the specific surfaces in the home designate certain meaning and serve to coordinate domestic life. In their study they focused on paper mail (ibid), and described how if for instance a letter is found by the porch, it suggests that no other person has dealt with it yet. Whereas if it is placed at the doorstep of the teenagers' door, it signals that it has passed some other household member, e.g. a parent, who may have recognized a letter from the phone-provider and expects the teenager to deal with it. Confirming the studies of Crabtree et al., but focusing on domestic information materials more broadly than paper mail, our studies also suggest that the spatial layout of the home is indeed used to coordinate and structure domestic information materials, and thus is a resource in designing domestic hypermedia.To indicate how different surfaces of the home have different meaning, some example characteristics are listed in Table 2 and examples from the homes are presented in Figure 3 and Figure 4.

\begin{tabular}{|l|l|l|}
\hline Surface & Example material & Surface characteristics \\
\hline $\begin{array}{l}\text { Notice } \\
\text { boards }\end{array}$ & $\begin{array}{l}\text { Emergency phone number } \\
\text { Prescriptions } \\
\text { Pictures from a wedding } \\
\text { Appointment with dentist }\end{array}$ & $\begin{array}{l}\text { Information which is 'one click away' } \\
\text { Contact information } \\
\text { Notifications } \\
\text { Memorable material }\end{array}$ \\
\hline Table & $\begin{array}{l}\text { Brochures from a recent visit in a theme park } \\
\text { Mixed pile of childrens' book, adults' book, } \\
\text { and unused wrapping paper } \\
\text { Unfinished shopping list, commercials }\end{array}$ & $\begin{array}{l}\text { Traces of earlier activities } \\
\text { Piles awaiting further distribution in the } \\
\text { home }\end{array}$ \\
\hline $\begin{array}{l}\text { Entrance } \\
\text { hall }\end{array}$ & $\begin{array}{l}\text { A book which need to be returned to the shop } \\
\text { A hat which must be worn when leaving the } \\
\text { home }\end{array}$ & $\begin{array}{l}\text { Things to remember to bring along when } \\
\text { leaving the home }\end{array}$ \\
\hline Shelves & $\begin{array}{l}\text { Collection of selected cookbooks, music } \\
\text { CDs, computer games. Illegal games are kept } \\
\text { in a closed cupboard. Only cool cookbooks } \\
\text { are on display in the common-room. Less } \\
\text { cool books are stored in a room where } \\
\text { visitors do not normally come }\end{array}$ & $\begin{array}{l}\text { Media collections. Not necessarily } \\
\text { sorted optimally for searching or } \\
\text { browsing but rather in terms of } \\
\text { aesthetics, and in terms of what people } \\
\text { wish to show to others. }\end{array}$ \\
\hline Frames & Picture collages, posters, etc.. & Staging of personal memory \\
\hline
\end{tabular}

Table 2: Examples of different surfaces and their characteristics 



Figure 3: Left: Dining table with brochure from a theme park recently visited. Right: Mixed pile of children's' book, adults' book, and unused wrapping paper awaiting further distribution in the home

Thus as the list suggest, we also see how different places in the house have different meanings and are used to structure domestic information material. We also see how other interest than supporting browsing and searching come into play when placing materials in homes. E.g. as illustrated in Figure 5, only selected cookbooks are placed so they are immediately visible to visitors whereas the rest of the collection is kept in a place where visitors not normally come. This is an example of what Palasmaa has described as "Home is a staging of personal memory. It functions as a two-way mediator - personal space expresses the personality to the outside world, but, equally important, it strengthens the dweller's self-image and concretizes his world order"(Palasmaa 1994, p. 6). As people behave this way, and their home become meaningful in this way, it is important to ensure that this is also supported in future domestic environments where domestic materials are digitized.


Figure 4: Left: Table in Entrance hall with a pile of things to remember when leaving the house. Figure 5: Midlle: Shelves in kitchen where selected cookbooks are on display. Right Shelves in home office, holding the other part of the cookbook collection.

The highly spatial distribution of physical materials onto a multitude of surfaces in homes stands in market contrast to what happens, as domestic materials become digitized and stored on a personal computer in the home. The PC essentially provides centralized and individualized access to digital materials. It lacks the spatial distribution, the persistence and visibility of physical materials on display in the home, as we see numerous examples of in our empirical material. Thus we need to learn from the qualities of physical material, which enable spatial information structuring in the home when designing domestic interactive spaces. 


\section{Lazy structuring and sustainability of structures}

As evident from the pictures in Figure 6, which are taken in the same home, the time invested in structuring material reflects relationship to material. On the left picture is a mix of different materials including bills and papers from the bank. Right we see a collection of carefully collected and indexed cartoons. This leads to concerns on the sustainability of structures in everyday life of the home as some structuring mechanisms impose more effort on the user than others. An example of this is a case, where a person started to annotate individual digital photos with names of persons and places on pictures making this content directly searchable. However, the person who had explored this facility stopped after having annotated only a fraction of his collection, simply due to the conflict between the size of his collection and the time and effort in annotating individual pictures.


Figure 6: Pictures from the same home. Letters from the bank etc. versus favorite cartoons

An additional example of breakdown of structuring mechanisms is the problem of scalability. As when for instance the collection of cartoons in left picture of Figure 7 becomes too big to be browsed through in terms of author. In right picture of Figure 7 we see an example where the collection is being re-structured. Here we see three different classifications on the same material at the same time. One part is placed in labeled boxes in order to provide unique location identification for each magazine. The intention is to exploit peer-to-peer digital metadata on the magazines to provide computer supported searching and browsing.
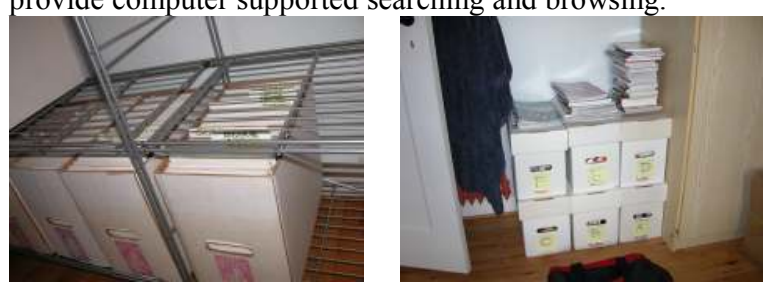

Figure 7: Different classifications on the same material - in this case cartoons

Another part is still ordered alphabetically by author. Finally a third part consists of the most recent issues. They are piled waiting for the owner to find time and mood to place them in the new categorization. This is in no ways a unique case. In the homes we saw numerous examples of half finished structures. This calls for an open hypermedia approach to domestic hypermedia, and for supporting lazy structuring of domestic materials. An example of a half finished structures and lazy structure of the physical material in the home is the widespread use of piles as a structuring mechanism. All the homes we visited had piles. Piles of bank papers and official papers waiting to be filed in binders. Piles of books on the dining table, waiting to be put in place. Thus piles are not as unstructured as it may first seem thanks to the meaning of different surfaces of places of the home, as 
discussed above. Some are piles of heterogeneous material, implicitly ordered by date, as sedimentations of materials. Not an effective structuring mechanism for a fast search, but a mechanism, which with the least possible effort still put some structure on the material largely due to the specific location of the pile. The pile in the entrance hall in Figure 4 is not sediment. It is carefully selected stuff which must be brought when leaving the home etc. Thus the specific context of the pile provides an additional layer of meaning to the structure. A dimension which is lost, if most domestic material can only be distributed on one, digital desktop.

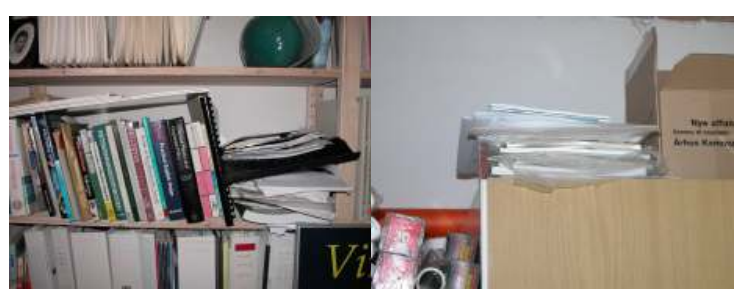

Figure 8: Piles as structuring mechanism in homes

\section{The structuring experience}

While one way to be pragmatic with respect to everyday life is to support lazy structuring mechanisms, an alternative and complementary approach is to design for playful and engaging structuring experiences thus aspiring people to take time to impose structure on their materials. The structuring experience provided by traditional PC's most often consists of individual manipulation of pull-down menus and dialogue boxes. Given the nature of the home, it would be interesting to investigate how collective and more playful structuring experiences can be supported.

\section{DOMESTIC HYPERMEDIA - FOLDING HYPERSPACES INTO THE HOUSEHOLD}

The empirical studies showed a lot of different ways of organizing physical material in the home. However, collaborative spatial organization and persistent visual awareness of the material seemed to be common means for the handling of domestic materials. In this section we propose a hypermedia concept that supports these approaches to structuring digital domestic material. We propose a hypermedia concept where digital hyperspaces are folded into the physical space. The notion of folding is inspired by the work on folding within architecture. In architectural foldings the idea is to create more dynamic and open buildings by folding rooms of one type in between rooms of another type, e.g. public spaces are folded into more private spaces and vice versa. As described by Lynn (1994) folding employs neither agitation nor evisceration but a supple layering. In such a way, that the characteristics of the individual layers are maintained. "A folded mixture is neither homogeneous, like whipped cream, nor fragmented like chopped nuts, but smooth and heterogeneous" (ibid p.9). 
empirical studies show that spatial organization and piling of material are very common structuring mechanism in homes as well as lazy or incomplete structuring is observed in many places. Thus DoHM in particular supports spatial hypermedia structuring integrating the connected physical surfaces. The DoHM infrastructure also supports carrying digital material around both inside and outside the home by means of having a physical token (like a cell phone or a smartcard) representing a persons digital portfolio on the home server and other integrated servers. The DoHM infrastructure is thus capable of handling the common structures that are used in homes, e.g. composites representing play lists, photo albums, and slideshows. Meta-data associated with physical objects or digital material like photos are represented in RDF. A central user interface for DoHM is the DoHM client, which provides a 2D spatial hypermedia interface including the registered surfaces as objects.

\section{Modelling home surfaces - presentation specifications and - styles}

The various surfaces in the private home needs to be addressable from the point of view of the hypermedia system, such that particular material can be presented in different (or even multiple) physical locations in the home. As discussed in above, surfaces in the private home serve many different purposes and exist in different contexts. E.g. things to remember when leaving the home are places persistently and visibly in the hallway. Whereas peripheral awareness of earlier activities is created through the traces of material left on dining table. This is implemented in the hypermedia model DoHM through adding two central concepts to the HyCon framework in order to handle representation and presentation. PlaceReps represent the place or context of a particular domestic hypermedia surface in the home; and PresStyles represent the style specification for a given object or surface. PlaceReps may represent both a specific place like "the refrigerator door" or an abstract place like "entrance" which may represent several physical locations in the home including, both hall, basement and terrace. Thus in this way, information that must be recalled when leaving the home can be displayed in all the physical entrances.

We wish to give the users maximum freedom in deciding how material in their home should be presented, to support the continuous appropriation of the home (Silverstone et al. 1992). We use Presentation styles to represent for the specific presentation style for a material object or a surface object. In light of the different nature of the different materials and surfaces I.e. some material on some surfaces should be able call for attention in some context, e.g. the appointment with the dentist on the notice board, which must be remembered, whereas others need to be discrete and aging, e.g. pictures from a recent weekend trip with friends. Thus we wish to support the users in specifying different presentation styles for material and surfaces in the home. For instance, a teenage kid may prefer to have a certain skin PresStyle associated with the surfaces reminding her of a favorite movie on every surface in the room. On the other hand, parents may want to associate an intrusive red colored notification PresStyle with a reminder note that they place on every relevant surface in the home. In this case there should be a combination strategy that allows both the teenager to maintain her surface skin and to be notified about the important note from the parents. This is solved by a calculation of the cascade based on the cascade priority attributes of the involved PresStyles. We currently explore different presentation styles, including persistent, aging, collage, highlight, surprise, animated, context-sensing. The Presentation styles will be subject to further experimentation and evaluation in an iterative design process.

\section{SUPPORTING COLLABORATIVE STRUCTURING AND UBIQUITOUS PRESENTATION}

In this section we describe some design concepts which are build upon the DoHM infrastructure and which addresses the need for collaborative structuring and ubiquitous presentation identified in the empirical studies. 


\section{MediaGates for piles of unsorted incoming material - supporting lazy structuring}

The DoHM system provides client support for uploading of digital material and scanning of physical material to the home server. The gate hardware will typically be scanners (for paper), FlashRam or USB ports (for pictures and documents), FireWire ports (for video). But email, SMS/MMS messages may also be transferred to gate space. The material being uploaded will be dropped onto a "gate" folder and canvas acting as temporary space for unsorted incoming material. This gate canvas can be associated with places in the home, where the family wish to create awareness of recent un-processed material. One such place may be the dining table which in homes is often used as a gate area for physical material in transition into other places in the home, e.g. see Figure 3. In this way we may support the lazy structuring witnessed in homes, as seen in Figure 7 and Figure 8.

\section{MediaTable: Augmented collaborative dining table - supporting new structuring experiences}

In many families, the dining table is a central place for coordinating activities, exchanging messages, and for organizing incoming materials. In the studies we have seen how families leave physical material on the dining table or the common room table creating a shared awareness in the home, before it is put away on a shelf or pinned to a notice board. When physical material becomes digitized it is often uploaded to or received on a computer somewhere in the home by one family member without reaching the attention of the rest of the family. In a future home with many digital materials we wish to be able to support collective coordination and organization of materials similar to the physical case. We are thus designing the DoHM client to support e.g. a dining table to be augmented with top projection and direct tangible interaction. The DoHM client present itself to the user as a spatial hypermedia interface, implemented in SVG (Scalable Vector Graphics) thus allowing elements to be turned around to be visible from arbitrary positions around the table, see Figure 12. The idea is that a common room table becomes a digital surface providing touch based interaction. The default view is the scratch area with incoming material and visual icons for the registered PlaceRep objects. In this way, family members become aware of new materials like incoming messages, new photos, new MP3s etc. Family members passing by can for instance drag a piece of material to a specific PlaceRep icon to make the material visible one or more surfaces in the home shown with the default PresStyle for these surfaces. In a situation where the family gather in the living room they may sit down or stand around the table and sort the piles of recent pictures into folders on the home server and drag some of them to specific PlaceReps to have them rendered on specific surfaces. They may also associate specific digital material with physical objects by means of RFID tags as described in (Grønbæk and Trigg 1999). The objects may be printouts of pictures or souvenirs like a concert ticket or a kids' doll, which then becomes a physical link anchor for a picture or a collection of pictures. Thus the table also aim to support collective organization of material thus supporting new types of structuring experiences as suggested from the empirical investigations. 


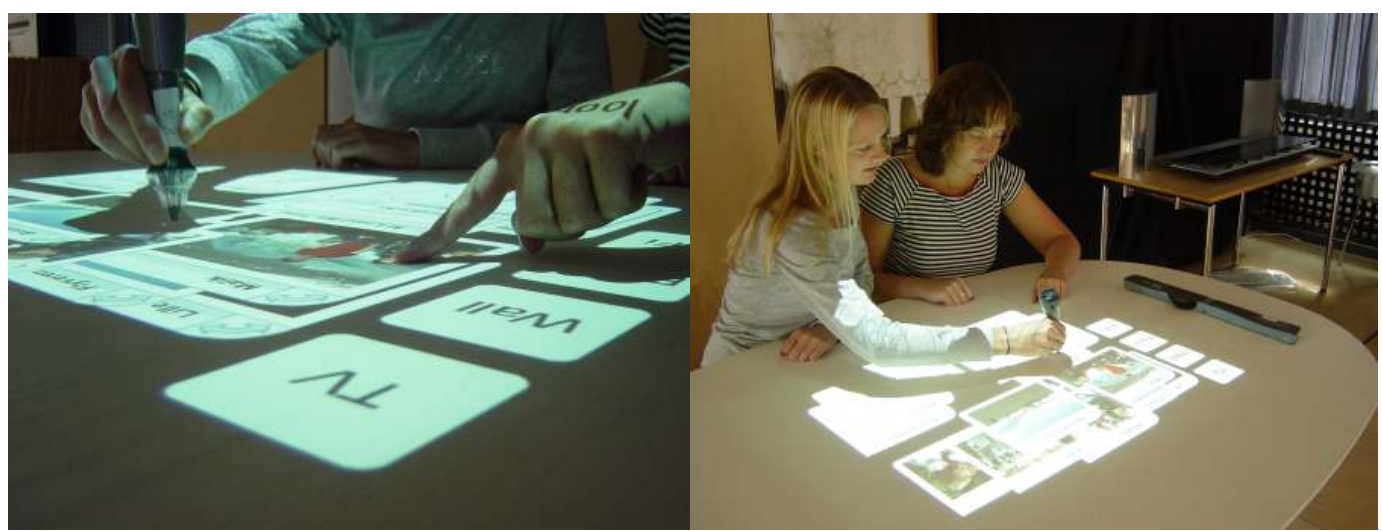

Figure 11: A scenario with two people interacting around a MediaTable Figure 12: The DoHM client as it looks when supporting collaborative picture sorting. The icons on the left are PlaceRep icons for surfaces in the home. The floating toolbars contain tools for interaction with objects.

\section{MediaTrays for physical link following}

The DoHM client may fold out into the physical world as a display less MediaTray (see Figure 13), which can be used both as a normal tray and as an interface for activating links by means of RFID tagged physical material. In the living room environment, a MediaTray placed on the sofa table may be used to start the playback of music on a connected HiFi set based on a physical object which has been associated the music. It may also be used to invoke a picture slide show on the TV based on a single printed picture being placed in the tray. In a kitchen environment a special MediaTray may be used to retrieve grocery declarations and recipes based on a piece of grocery material being put on the tray. The MediaTray is a display less hypermedia interface; it needs to integrate seamlessly with the environment without having to be configured via menus and dialogs. Thus the MediaTray needs to take advantage of its context such as the nearest HiFi set, TV set or other surface. If the tray is physically moveable, it just needs to be registered to a new location, and then it automatically takes advantage of the new context, similar to the physical hypermedia system for architects discussed by Grønbæk et al (1999).

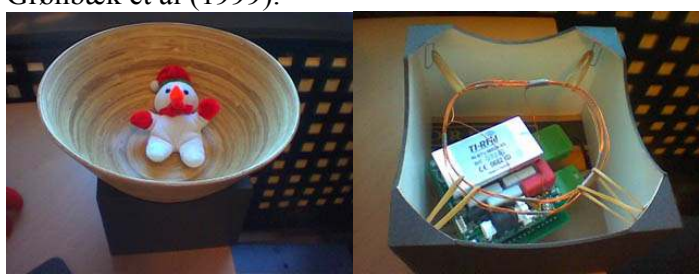

Figure 13: MediaTray for physical hypermedia interaction. The right picture shows the RFID tagreader in the bottom. 


\section{MediaWall: Calm awareness support}

In order to exploit the potential of surfaces in the home, we have developed the concept of the MediaWall. Messages and notes often contain contents to be remembered and to be used at certain points in time. Thus some sort of notification service is needed, as when the appointment with the dentist must be remembered. However, few people wish to have there home filled with notifications in terms of active alarm clocks. In contrast, the MediaWall offers the quality of ubiquitous and persistently visible message. Maintaining awareness about important material or critical events is supported in the DoHM system. Here we will focus on the discrete or calm (Weiser and Brown 1996) awareness based on discrete visual appearance. We are inspired by the notions of Informative arts (Holmquist and Skog 2003, Redström et al. 2000) as well as InfoCanvas (Millar and Stasko 2001). The idea is to provide awareness about important material through an artistic collage of the material on one or more surfaces. To support this we are taking advantage of the open hypermedia techniques for anchoring links in arbitrary Web pages. Here we let family members make selections on arbitrary Web pages including the home server, submitting the corresponding anchors to a collage service together with a PlaceRep with a 'Collage' PresStyle. The surface identified by the PlaceRep will then display the selected text and graphics corresponding to the anchor according to some schema with an expression designed to fit the actual room and the inhabitant's preferred level of calmness. The collage service is meant to maintain an ongoing awareness of the updated view of information identified by the submitted anchors, thus an active crawler is need to regularly collect information from servers, filtering the parts of the pages needed, making an artistic transformation before the representation is dispatched to the surfaces pointed out by the PlaceReps that were associated with the anchor when submitted to collage service.

\section{CONCLUSIONS}

The MediaGate, the MediaTable, the MediaTray and the MediaWall together presents a vision of a domestic hypermedia system, which takes into account the specific challenges of the household. The MediaGate address the challenge of lazy structuring, the MediaTable offers new structuring experiences, the MediaTray provide new ways of linking digital and physical materials, and the MediaWall takes advantage of the meaning and richness of the surfaces of the home. In this paper we have demonstrated how we apply the perspective of interactive spaces to maintain a focus on supporting interaction among people who are co-located. We have presented an empirical study of the use of primarily physical material in private homes and we have illustrated how taking the context of the home seriously implies certain challenges for domestic hypermedia. Designing for the pragmatics of real domestic life implies for instance supporting lazy structuring of domestic materials. It implies using the rich set of surfaces of the home as a resource in design, and it implies exploring how collective and more playful structuring mechanisms can be developed. Based on the challenges revealed in these studies we have described the design of a new Domestic Hypermedia infrastructure called DoHM, which supports the folding of spatial and navigational hypermedia into the physical environment of a home. We have presented a couple of novel home appliances that take advantage of the DoHM infrastructure and fold the hyperspace into the living room. We have established the basic DoHM infrastructure and are initiating the initial experiments with users introducing the appliances being designed. We have developed the first lab prototypes of the appliances and the DoHM infrastructure, and they will be evaluated both in our lab and in specific home settings within the coming months. 


\section{REFERENCES}

Bouvin, N.O., Christensen, B.G., Grønbæk, K., Hansen, F.A. HyCon: A Framework for Contextaware Mobile Hypermedia. 2003. To appear in NRHM journal volume 9.

Crabtree, A., Hemmings, T. and Rodden, T. (2002a) "Coordinate displays in the home", CSCW Workshop on Public, Community and Situated Displays, Proceedings of the 2002 ACM Conference on Computer Supported Cooperative Work, New Orleans: ACM Press.

Crabtree, A., Hemmings, T., and Rodden, T. (2002b) Patternbased Support for Interactive Design in Domestic Settings. In Proc. of DIS2002, ACM Press, pp. 265-275.

Eggen, B., Rozendaal, M. and Schimmel, O. (2003). Home Radio - Extending the Home Experience beyond the Boundaries of the Physical House. In Proceedings of the Home Oriented Informatics and Telematics, University of California, Irvine, April 6-8, 2003.

Grønbæk, K. \& Trigg, R.H. From Web to Workplace: Designing Open Hypermedia Systems. MIT Press, Boston Massechussets. July 1999, 424 pp (ISBN 0-262-07191-6).

Grønbæk, K., Ørbæk, P., Kristensen, J.F., and Eriksen, M.A. Physical Hypermedia: Augmenting Physical Material with Hypermedia Structures. To appear in New Review of Hypermedia and Multimedia (NRHM). Vol 9. 2003.

Holmquist, L. E., and Skog, T. (2003) Informative Art: Information Visualization in Everyday Environments. In Proc. of the first intl. conference in computer graphics and interaction techniques in Australia and Southeast Asia.

Humble, J., Hemmings, T., Crabtree, A., Koleva, B. and Rodden, T. (2003) “"Playing with your bits': user-composition of ubiquitous domestic environments", Proceedings of the 5th international Conference on Ubiquitous Computing, pp. 256-263, Seattle: Springer.

Hutchinson, H., Mackay, W., Westerlund, B., Bederson, B. B., Druin, A.,Plaisant, C., BeadoinLafon, M., Conversy, S., Evans, H., Hansen, H., Roussel, N., Eiderbäck, B., Lindquist, S., and Sundblad, Y. (2003) Technology Probes: Inspiring design for and with families. In Proceedings of CHI 2003. ACM Press, pp.

Kjær, A., Madsen, K. H. \& Petersen, M. G. (2000) Methodological Challenges. In The Study Of Technology Use At Home. In Home Informatics and Telematics: Information, Technology and Society, Sloane, A. and van Rijn, F. (Eds.) Boston: Klüwer Academic Publ., pp.45-60

Lynn, G. (1994) Architectural curvilinearity : The Folded, the Pliant and the Supple. In Folding in Architecture. Architectural Design Magazine. Academy Grp Ltd., pp. 8-15.

Marshall, C., \& Shipman, F. Spatial hypertext and the practice of information triage, In Proc. Tenth ACM Conference on Hypertext (Hypertext '97). (Southampton, UK, Apr, 1997), pp. 124133.

Millar, T., Stasko, J. (2001) The InfoCanvas: Information Conveyance through Personalized, Expressive Art. In Proceedings of CHI 2001, ACM Press, pp. 305-306.

Monk, A. (2000) User-Centred Design. The Home use challenge. In Sloane, A. \& van Rijn, F. Home Informatics and Telematics. Information, Technology and Society. Kluwer Academic Publishers, pp. 181-190.

Mynatt, E., Rowan, J., Jacobs, A., and Craighill, S. (2003) Digital Family Portraits: Supporting Peace of Mind for Extended Family Members. In Proceedings of CHI 2001, ACM Press, pp. 333-340.

Pallasmaa, J. (1994) Identity, Intimacy and Domicile. Notes on the phenomenology of home. In Finnish Architectural Review $1 / 1994$.

Petersen, M. G., Madsen, K. H. and Kjær, A. (2002) Usability of Everyday Technology - Emerging and Fading opportunities. In ACM Transactions on Computer-Human Interaction, Vol. 9, No. 2, June 2002, pp. 74-105. 
Petersen, M. G. and Baillie, L. (2001) Methodologies for Designing Future Household

Technologies. In Proceedings of the OIKOS2001 Workshop, Aarhus University Press, pp. 47-49

Premkumar, G. P. (2003) Alternate distribution strategies for digital music. In Communications of the ACM, September, Volume 46, Issue 9.

Redström J, Skog T \& Hallnäs L. Informative Art: Using Amplified Artworks as Information Displays. In Proceedings of DARE 2000, Designing Augmented Reality Environments, ACM, 2000, Elsinore, Denmark

Silverstone, R., Hisch, E. \& Morley, D. (1992) Information and communication technologies and the moral economy of the household. In Consuming Technologies. Media and Information in Domestic Spaces. Routledge. London and New York. pp. 15-31.

Tolmie, P., Pycock, Diggins, T., MacLean, A., and Karsenty, A. (2001) Unremarkable Computing. In Proceedings of CHI2002, ACM Press, pp. 399-406.

Weiser, M. \& Brown, J.S. (July 1996) "Designing Calm Technology", PowerGrid Journal, v 1.01.

\section{COPYRIGHT}

[Author/s names] (C) 2004. The authors assign to OZCHI and educational and non-profit institutions a non-exclusive licence to use this document for personal use and in courses of instruction provided that the article is used in full and this copyright statement is reproduced. The authors also grant a non-exclusive licence to OZCHI to publish this document in full in the Conference Papers and Proceedings. Those documents may be published on the World Wide Web, CD-ROM, in printed form, and on mirror sites on the World Wide Web. Any other usage is prohibited without the express permission of the authors. 